\title{
Response to Letter to the Editor-"Soil biofilms": Misleading description of the spatial distribution of microbial biomass in soils
}

\author{
Peng Cai ${ }^{1{ }^{*},}$ Yichao $\mathrm{Wu}^{1}$, Marc Redmile-Gordon ${ }^{2}$ \\ 1 State Key Labor atory of Agricultural Microbiology, College of Resources and Environment, Huazhong Agricultural University, \\ Wuhan 430070, China \\ 2 Department of Environmental Horticulture, Royal Horticultural Society, Wisley, Surrey, GU23 6QB, UK
}

(C) Higher Education Press 2020

Thank you for the interest in the article of soil biofilms. We are happy to discuss this topic. Firstly, we should clarify something crucial: at no point has the term "soil biofilm" been used to describe the soil microbial biomass. We have always maintained that biofilms comprise microbial biomass and EPS as distinct pools. Therefore, the title of the above article, "Soil biofilms": Misleading description of microbial biomass, is itself misleading.

To address specific points, in the above letter, the author suggests that the concept of biofilms existing in soil is problematic, because 1) sparse evidence showing bacteria covering the internal surface of soil uniformly or patchily; 2) the failed description of biofilms in porous media using the traditional diffusion-limited model. However, neither of these two points are convincing arguments against either 1) the existence of biofilms in soil, or 2) the value of considering biofilms in soil.

Firstly, biofilms can be supported at solid-liquid, liquid-liquid, liquid-gas interfaces (Characklis and Wilderer, 1989). Therefore, biofilms are not only found on solid surfaces. The cell aggregates in the lumen of pores (Figure $3 b$ of (Vandevivere and Baveye, 1992)) are biofilms. In the soil environment, multicellular aggregates embedded in EPS (biofilms) were also observed via SEM or TEM (Figure 1.3 of (Watteau and Villemin, 2018) and Figure 5 of (Eickhorst and Tippkötter, 2008)), which is the direct evidence of soil biofilms. Moreover, the failure of traditional modelling of biofilms is irrelevant. The discrepancy between model predictions and observations in porous media was mainly attributed to the heterogeneous

Received January 15, 2020; accepted January 30, 2020

* Corresponding author

E-mail address: cp@mail.hzau.edu.cn (P. Cai) distribution and permeability of that biofilm. Therefore, while we concede that it should not be assumed that the majority of soil microbial biomass exists embedded in EPS (as a biofilm), the existence of biofilms in soil environments is in fact supported by several studies. Furthermore, since biofilms are known to drive biogeochemical processes and affect the physical arrangement of biology with host media (Flemming and Wuertz, 2019), the advances of soil biofilm research can provide a clearer picture of microbial-mediated biogeochemical processes and help to develop sustainable soil management practices.

Finally, the above letter raises an important point regarding assumptions: "By not assuming more about the spatial distribution of microorganisms than what we know, I feel that we would not only be far more consistent with the findings of a significant body of literature that cannot be bypassed, but also we would also approach the research from a much sounder conceptual vantage point." In isolation, this is indeed a sound statement. However, we feel it does not support the content or main thrust of the original letter, because understanding of the term "biofilm" is incorrectly presented, and ironically seems based on outdated assumptions: "Fourty years ago, biofilms were thought to cover surfaces uniformly, hence the term of 'film', but it has since become obvious that in many instances, for a variety of reasons (e.g., hydrodynamics, predation), biofilms are more likely to be patchy than to cover surfaces entirely."

We could not agree more that biofilms in soils are likely to be "patchy", indeed, this led to the current understanding, that a biofilm is a co-habiting group of microbial cells (typically at an interface) surrounded by a matrix of extracellular polymeric substances (EPS; Redmile-Gordon et al., 2014; Cai et al., 2019) and this modern viewpoint is shared by other researchers in other environmental disciplines. This modern definition is 
much clearer than the outdated "uninterrupted all-pervasive film" idea (indeed, where one draw the boundary) and much more specific than ad-hoc modification by introducing the term "patchy" into the above (because the next question would be at what scale does one define a patch? which of course, would be arbitrary). We therefore agree that to avoid confusion researchers should neither make assumptions 1) on the distribution of cells in a biofilm, nor 2) on the distribution of biofilms in a soil. However, we maintain that the existence of collections of microbial cells (or "biomass") embedded in EPS on soil particles ("biofilms") is undeniable.

\section{References}

Cai, P., Sun, X.J., Wu, Y.C., Gao, C.H., Mortimer, M., Holden, P.A., Redmile-Gordon, M., Huang, Q.Y., 2019. Soil biofilms: microbial interactions, challenges, and advanced techniques for ex-situ characterization. Soil Ecology Letters 1, 85-93.
Characklis, W.G., Wilderer, P.A., eds. 1989. Structure and Function of Biofilms. John Wiley, New York.

Eickhorst, T., Tippkötter, R., 2008. Detection of microorganisms in undisturbed soil by combining fluorescence in situ hybridization (FISH) and micropedological methods. Soil Biology and Biochemistry $40,1284-1293$.

Flemming, H. C.; Wuertz, S., 2019. Bacteria and archaea on Earth and their abundance in biofilms. Nature Review Microbiology 17, 247260.

Redmile-Gordon, M.A., Brookes, P.C., Evershed, R.P., Goulding, K.W. T., Hirsch, P.R., 2014. Measuring the soil-microbial interface: Extraction of extracellular polymeric substances (EPS) from soil biofilms. Soil Biology and Biochemistry 72, 163-171.

Vandevivere, P., Baveye, P., 1992. Saturated hydraulic conductivity reduction caused by aerobic bacteria in sand columns. Soil Science Society of America Journal 56, 1.

Watteau, F., Villemin, G., 2018. Soil Microstructures examined through transmission electron microscopy reveal soil-microorganisms interactions. Frontiers in Environmental Science 6, 106. 